
Not for reproduction, distribution or commercial use.

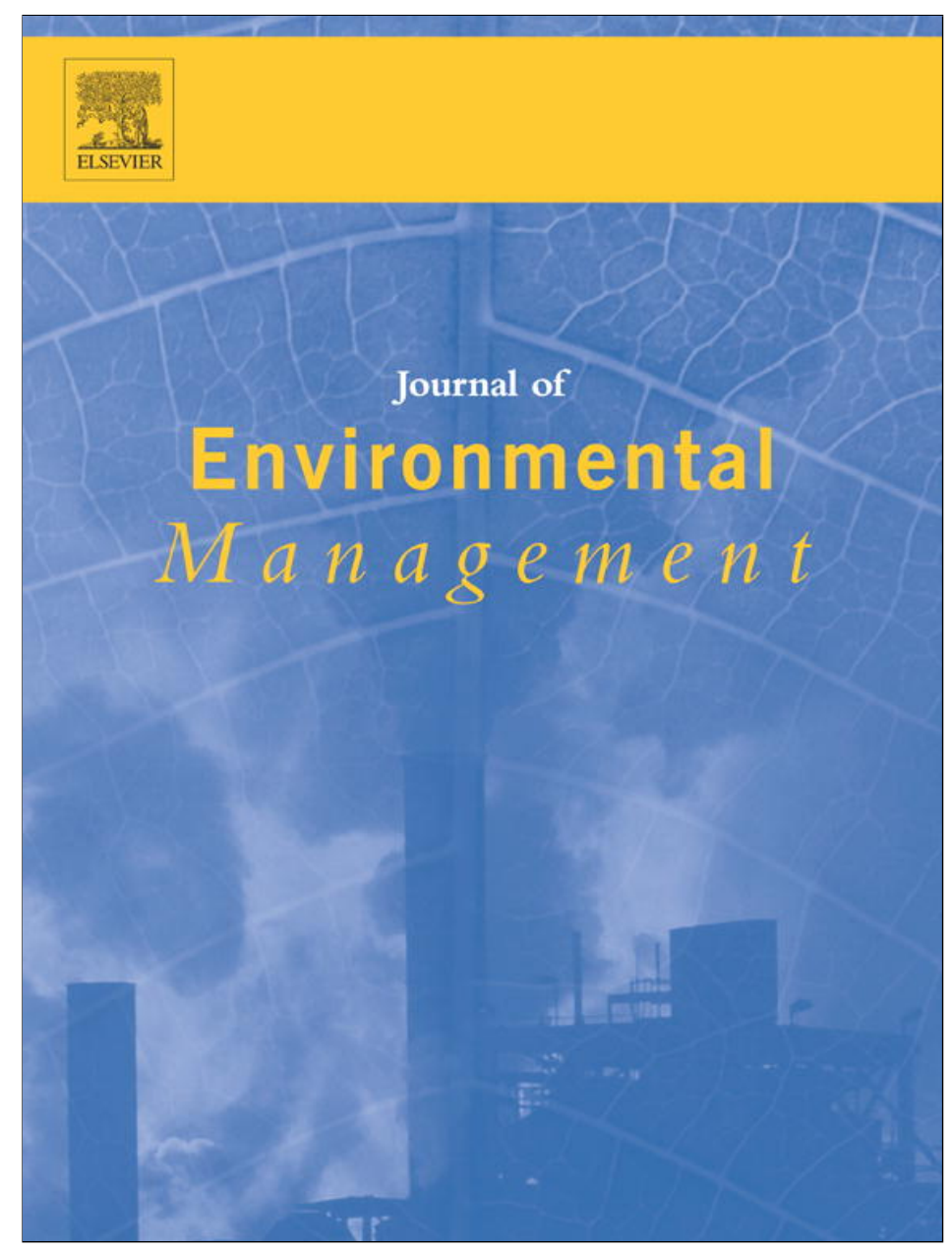

(This is a sample cover image for this issue. The actual cover is not yet available at this time.)

This article appeared in a journal published by Elsevier. The attached copy is furnished to the author for internal non-commercial research and education use, including for instruction at the authors institution and sharing with colleagues.

Other uses, including reproduction and distribution, or selling or licensing copies, or posting to personal, institutional or third party websites are prohibited.

In most cases authors are permitted to post their version of the article (e.g. in Word or Tex form) to their personal website or institutional repository. Authors requiring further information regarding Elsevier's archiving and manuscript policies are encouraged to visit: 


\title{
Environmental planning and management in an age of uncertainty: The case of the Water Framework Directive
}

\author{
Jeremy G. Carter*, Iain White \\ School of Environment and Development, University of Manchester, Oxford Road, Manchester M13 9PL, UK
}

\section{A R T I C L E I N F O}

\section{Article history:}

Received 16 January 2012

Received in revised form 17 May 2012

Accepted 23 May 2012

Available online

\section{Keywords:}

Scenarios

Future studies

Environmental planning

Uncertainty

Water Framework Directive

Decision making

\begin{abstract}
A B S T R A C T
Scenario planning is one of the most prominent methods applied by organisations to assist long-term decision making. This paper uses a case study method to demonstrate how scenarios can be operationalised to inform future strategies and to challenge rigid silo-based decision making approaches. The WaterProof Northwest scenarios developed by the authors in collaboration with a range of stakeholders, and described within this paper, offer a platform for considering the future of the water environment. The scenarios were developed in the context of meeting the goals of the European Water Framework Directive. This Directive has the core aim of improving the chemical and ecological status of Europe's water bodies. The scenarios highlight that water bodies in the case study area (the region of Northwest England) are impacted directly by a wide array of driving forces which will affect the state of the water environment over the coming decades. This analysis demonstrates that organisations responsible for creating and implementing long-term plans and policies to manage water are often far removed from the forces that will influence the effectiveness of the exercises that they are engaged in. The WaterProof Northwest scenarios highlight that organisations need different decision making approaches in order to adapt to modern environmental challenges. They also raise questions over whether environmental legislation such as the Water Framework Directive should incorporate a futures perspective in recognition of the wide ranging forces influencing their implementation.
\end{abstract}

(c) 2012 Elsevier Ltd. All rights reserved.

\section{Introduction}

Analysing recent trends, integrating varied potential drivers of change and subsequently intervening through strategy and plan making to positively shape the future lies at the core of environmental planning. There is an implicit need to incorporate a 'futures perspective' in this field, and given this need, individuals and organisations should ideally be skilled at responding to uncertainty and complexity as part of the development of long-term strategies and forward plans. However, methods and approaches to analyse and respond to future uncertainties are not widely engaged with nor applied. Over recent decades, an increased level of awareness of the sheer unpredictability of complex natural and constructed systems has begun to emerge as societies experience the impacts of synergistic crises and powerful individual events (Brown et al., 2010). Changing climates, global financial crises and natural disasters affect economies, nations and ecosystems across the

\footnotetext{
* Corresponding author. Tel.: +44 1612756882.

E-mail addresses: jeremy.carter@manchester.ac.uk (J.G. Carter), iain.white@ manchester.ac.uk (I. White).
}

globe, highlighting the presence of external forces that lie beyond the control of even the most seemingly sophisticated organisational structures (Renn, 2008; Smil, 2008; White, 2010). Anticipating and incorporating these complex issues within environmental planning can bring significant benefits. However, the development of long-term strategies, plans and decisions are hampered by often narrow disciplinary, geographic or temporal foci of organisations. As understanding of the interconnected and global-localising nature of modern society deepens, planning and decision making practices should also evolve to better prepare actors and agencies for these wider, and progressively more dynamic, drivers of change.

In order to best serve the public, scientists and policy makers have a responsibility to recognise and respond to evolving circumstances that influence societies, economies and natural environments. All too often, however, responses materialise after a serious event has been experienced or a 'weak signal' becomes magnified. The increased risk of New Orleans to catastrophic flooding by a gradual erosion of natural defences and inappropriate development had been highlighted prior to Hurricane Katrina in 2005 (Wisner et al. 2004), yet this insight did not alter practice in order to lessen this risk. Whilst it is reasonable to assume that not 
all such risks can be anticipated, in the New Orleans case the data was there and the threat identified. It is clear that evidence of a problem, identification of tangible causal chains and the proposal of possible solutions does not always provide a strong enough argument to motivate changes to plans or processes until after a detrimental event.

Although it is increasingly understood that many events have a direct or indirect influence way beyond their perceived sphere, to be more resilient to change there is a clear need to build strategic thinking into the process of developing strategies and forward plans. Whilst it is acknowledged that damaging events do have the potential to set agendas (Kingdon, 1984) or create momentum for policy change, for example in the case of flood risk management (Johnson et al., 2005), this is clearly an unsustainable, reactive process. There is real value in adopting a more long-term strategic view supported by appropriate tools and techniques, and developing a knowledge base to help better respond to the possible array of future uncertainties.

Enhancing knowledge and awareness of the dynamic nature of problems affecting society, and their potential implications, is a precursor to understanding how best to adapt governance structures and decision making processes. Taking this broad challenge as its starting point, this article provides theoretical and practical insights into addressing uncertainty and complexity with a particular focus on environmental planning. Broad themes related to the motivation for, and methods lying behind, future thinking are discussed. Specific focus is paid to scenarios, which have emerged as a key route for embedding futures perspectives into planning and decision making. The WaterProof Northwest project, which developed scenarios to incorporate a long-term perspective within water management in Northwest England, is analysed as a case study (Carter and White, 2010). WaterProof Northwest is discussed in the context of the methods employed and the transferable learning that the process, and the interpretation of its outcomes, generated. Particular attention is paid to the European Water Framework Directive, which set an important context for the development of the WaterProof Northwest scenarios.

This article aims to stimulate a wider appreciation of the value of scenario development as a tool to address the inherent uncertainty and complexity that characterises environmental decision making, and increase awareness of how this approach can be applied in practice. The insights contained with this article, including the learning generated from engaging in the process of scenario development, can support proactive future-oriented decision making in the field of environmental planning and management.

\section{Futures methods}

"We can either stumble into the future and hope it turns out alright or we can try and shape it. To shape it, the first step is to work out what it might look like".

(Ladyman, 2006)

The view that some issues are just too complex to be resolved by standard, linear and analytical approaches is not a new one. Rittel and Webber (1973) compartmentalised problems into two types: tame problems and wicked problems, where the latter may be multicausal, dynamic, subject to ambiguity, and importantly, resist resolution. In addition to this complexity, the high degree of uncertainty characterising many contemporary issues was highlighted by Funtowicz and Ravetz (1991) who advocated that we should move towards 'post-normal' science; reflective of a situation where data may be limited and normal planning and decision making approaches may not be equipped to provide timely interventions. Owens and Owens (1991) have also questioned the effectiveness of the traditional environmental policy and planning cycle, which may create implementation gaps inhibiting action, particularly where information is hard to quantify, problems are complex and the distribution of related costs and benefits varies spatially and temporally.

Despite the high degree of uncertainty that characterises the description and analysis of forces with the potential to shape the future, planners and decision makers must continue to develop and implement long-term plans and strategies that aim to maintain and improve environmental quality. Indeed, there are often legislative mechanisms in operation at supra-national and national scales that mandate the production of such plans and strategies in fields including water management, nature conservation and flood risk management (European Union, 2000, 2007). The long time horizons that characterise such legislation implies the need for methods and approaches that offer a means of embedding 'future thinking' and 'horizon scanning' into environmental planning. Further, the increased focus on sustainable development over recent years, and the intergenerational timescales that this concept implies, has moved the task of considering potential future patterns of growth and development to the centre of policy and scientific agendas (Rankin, 2005).

Perhaps as a result of the uncertainty influencing environmental planning and management agendas and the associated challenges for planners and decision makers, Skaburskis and Teitz (2003) state that spatial planners have tended to overstate and exaggerate future forecasts when these are compared with eventual outcomes. They cite reasons for overstating future conditions and outcomes, including limited knowledge of the complex processes affecting cities and social networks (and how these systems and processes function themselves), errors in estimation based on projecting forward past trends, limited information on relevant issues and institutional factors affecting the forecasters. Exaggerated predictions may also result from an underestimation of the power of individual and collective behaviour change that can act to moderate the impact of emerging trends (Skaburskis and Teitz, 2003).

There is, however, a range of decision aiding tools and techniques that can help to overcome some of the pitfalls of forecasting outlined above, enabling a more nuanced perspective of possible future conditions to be gained. These can be broadly categorised according to the time horizons that they focus on. Quantitative trend analyses are data driven approaches generally used to make near-term projections based on existing trends using mechanical and sometimes statistical methods. These include time-series forecasts and trend extrapolations, which are used to project forward relatively stable systems and processes such as demographic change. Their objective nature makes such approaches easy to communicate, but they generally fail to address dynamic processes that are not easy to quantify. Also, as noted by the Cabinet Office (2001: 6) trend analyses are "...extrapolations of the past..." and should therefore ideally be complemented by with qualitative approaches that provide scope to incorporate the consideration of future drivers of change. Indeed, predictive modelling is not well suited to studying complex and integrated social and ecological systems that are strongly influenced by human behaviour (Rankin, 2005).

Qualitative trend analyses, which generally have a longer term focus, are based on the notion that many of the seeds of the future are contained within the present, although relevant information is often widely dispersed and difficult to extrapolate. Investigating potential 'mega-trends' across the fields of society, politics, environment, economics and technology is one route into gaining a better understanding of forces that could exert a significant influence over the future of a defined topic. This process is also referred to as 'horizon scanning.' Looking beyond the traditional 
scope of scenario exercises brings into consideration 'wild cards' and 'weak signals' (Brown et al., 2010). Wild cards are high impactlow probability events that can emerge from natural (e.g. earthquakes, tsunamis, volcanoes) or human systems (e.g. the collapse of the Berlin Wall or the Fukushima nuclear accident). Wild cards can emerge as a result of weak signals or 'background noise' in a system that can sometimes provide an indication of a significant event or period of change on the horizon. Such issues are sometimes incorporated into scenario exercises as 'shocks' that lead to fundamental shifts in societal behaviour or geo-politics. Techniques for investigating mega-trends, wild cards and weak signals include stakeholder workshops and Delphi surveys, the latter being a method through which a panel of selected experts anonymously contribute to a process of identifying key themes related to the future of a particular topic. The Delphi Technique has a history of application in the public, private and academic sectors (Hsu and Sandford, 2007), and has been described by Linstone and Turoff (1975: 3) as: "a method for structuring a group communication process so that the process is effective in allowing a group of individuals, as a whole, to deal with a complex problem".

The 'drivers of change' identified by quantitative and qualitative trend analyses form a starting point for scenario development. Scenarios are one of the most well recognised and commonly applied strategic futures methods. They are now considered in greater detail including an overview of, and lessons learnt from, a recent scenario exercise conducted by the authors within the WaterProof Northwest project.

\section{Scenarios: history and application}

A scenario is essentially an imagined sequence of future events. Scenarios are not predictions or forecasts, and levels of probability are not assigned. Instead, they can be most effectively viewed as vehicles through which different possible future conditions are explored. In some cases their implications are assessed through modelling exercises. The aim of scenario exercises is not to paint an accurate picture of how the future will unfold, and so outcomes should be treated with caution to avoid misinterpretation by groups who may not fully understand the nature of the scenario process. Rather, scenarios can help individuals and organisations develop a longer term 'futures perspective' that acknowledges uncertainty and embraces this as a key feature of strategic planning exercises. Scenarios can enable the construction of future visions to be cultivated and in some cases avoided, and used in this way they can provide a powerful nexus for individuals and organisations to gather around.

Several reviews have been undertaken that provide an overview of different scenario approaches (Bishop et al., 2007; EEA, 2000, 2001; Van Notten et al., 2003; Voros, 2006). In a professional context, scenarios trace their origins back to military planning exercises undertaken around the start of the Cold War. It was not until the futures studies of the 1970's that scenarios began to mesh narrative approaches with modelling techniques (Rankin, 2005), often focussing on issues related to environmental sustainability. An early example of this approach was The Limits to Growth report (Meadows et al., 1972). This study utilised a systems dynamics model to develop scenarios to consider the implications of global driving forces on prospects for human development through to the end of the 21st Century. One of the most influential scenario sets of recent years is the IPCC greenhouse gas emissions (GHG) scenarios (IPCC, 2000), which act as a key input to global climate change models that then project future changes to climate and weather variables. Key driving forces with the potential to influence levels of future GHG emissions are reflected within the scenarios, including demographic, technological and economic issues. Variations in the direction of these driving forces and the relationships between them lead to significantly diverging atmospheric GHG levels over the 21st Century. Consequently, resulting climate change projections display a wide range of possible outcomes depending on the chosen emissions scenario. The IPCC example demonstrates how the scenario method now finds itself at the heart of global environmental policy and planning.

Scenarios are now used across the public, private and third sectors. There are several circumstances where scenarios are commonly developed and used by stakeholder groups and organisations. These include introducing a futures-oriented perspective into long-term planning processes, for example when creating a new vision or mission statement for an organisation. In addition to influencing strategic policy, scenarios can also be useful during the development of forward plans, particularly those that will have long-term consequences. These include land use plans, where scenarios are of value in assessing the strengths and weaknesses of different land use options designed to guide the future growth and development of cities or regions for example. In essence, scenarios offer an opportunity to interrogate the potential performance of strategies, policies and actions under different future conditions.

Scenarios can also be usefully applied where an organisation or a sector is anticipating or experiencing change either as a result of internal restructuring or the impact of external forces. However, if an organisation waits until it is hit by 'turbulence' it can often be too late to respond effectively. Indeed, it can take a large organisation up to five years to respond to significant changes in its external operating environment, a time span that Shell have aimed to reduce to eighteen months by incorporating scenario thinking (The Henley Centre, 2001). It is beneficial for organisations to internalise a strategic long-term view into their planning processes and operations by building horizon scanning capacity. Used in this way, scenarios can act as an early warning device highlighting emerging issues that organisations could usefully address through additional research, action or strategy development.

Scenario development is generally a participatory process. Indeed, scenarios are social products emerging from a social process (Garb et al., 2008). Developing and working with scenarios within real-world planning and policy making settings can help individuals and organisations to challenge their 'worldview' and perceptions of how the future may unfold. Scenarios are therefore a valuable educational and awareness raising tool. Due to their ability to encourage collaboration between scientists, policy makers and the public, the process of scenario development can be regarded as equally if not more important that the end product (Clark et al., 2006). Further, using scenarios in practice can act as a catalyst for the participation of a diverse range of stakeholders in a workshop setting, bringing a broader range of individuals into the decision making process. Here, scenarios can help to broaden consideration of the scope of possibilities influencing particular decisions or actions. In addition, the development of collaborative links between related sectors and agencies may strengthen the implementation of forward plans or project actions. However, some caution must be exercised here in that scenarios are effectively a process of negotiation about the future that takes place between a number of actors with a stake in that future. As a result of the social nature of the process there is the danger that powerful groups will seek to 'colonise' future visioning exercises for their own ends (Sadar, 1999).

Research into the use of scenarios suggests that they can stimulate benefits including making decisions more robust, strengthening organisational performance, and enhancing policy making (Bezold, 2010; EEA, 2009). In this context, Hulme and Dessai (2008) distinguish between determining the predictive success, decision success and learning success of scenario exercises. Echoing the 
potential value of scenarios as a vehicle for challenging perceptions and worldviews, Wack (1985) believes that a key criterion for determining the effectiveness of scenarios concerns the extent to which they can perform this function. More research is needed to demonstrate the benefits of scenarios in practice, which could help to strengthen the uptake of the process.

\section{WaterProof Northwest: exploring the implementation of the Water Framework Directive using scenarios}

The WaterProof Northwest scenarios, developed by the authors working collaboratively with a group of stakeholders, aimed to introduce a futures perspective into the consideration of the water environment and water resources in Northwest England. The Water Framework Directive (WFD) provided an important legislative background for the scenario development process. The WFD is Europe's most ambitious piece of water management legislation, streamlining previously separate water related legislation under one umbrella (European Union, 2000). The purpose of the WFD is to develop a framework to protect and prevent further deterioration of Europe's water bodies, including inland surface water, transitional water, coastal water and groundwater. Article 4 of the Directive sets out its core environmental objectives, which centre on the achievement of 'good water status' in Europe's water bodies by 2015 , although there are exceptions enabling this date to be postponed to 2027 providing that no further deterioration of the status of water bodies occurs (European Union, 2000). The assessment of water status encompasses ecological and chemical dimensions.

Taken together, the objectives of the WFD outline the basic principles of a comprehensive, holistic and sustainable approach to European water management. Looking beyond the good water status objective, other key elements of the Directive include (following Chave, 2001):

- Encouraging the sustainable use and protection of water supplies.

- Protecting and enhancing the aquatic environment (habitats and species).

- Reducing point source and diffuse pollution to surface and groundwater bodies.

- Helping to mitigate the effects of floods and droughts.

To achieve these objectives the Directive requires the development of River Basin Management Plans (RBMP) and associated 'programmes of measures' to implement water management actions. An economic analysis of the potential costs of proposed measures must be provided. The plans outline how the objectives of the WFD will be met in the river basin within the required timescale. Focussing at the river basin scale challenges many institutional norms as this adheres to natural geographical and hydrological boundaries, rather than the traditional emphasis of water management on administrative and political borders.

The Environment Agency (the central government agency responsible for protecting and improving the environment of England and Wales, including delivering the WFD) anticipates that meeting the objectives of the Directive for the Northwest region of England will take to 2027 (Environment Agency, 2009). There is considerable uncertainty surrounding the future direction of key drivers of change, such as economic growth or technological change for example, which will impact on water quality and quantity issues over these timescales. The WaterProof Northwest project was conceived to respond to this issue through developing a set of scenarios to give an insight into how the Northwest region and its water environment might evolve over the coming decades.
Raising awareness of related issues through the creation and analysis of the WaterProof Northwest scenario set provides additional insights into the challenges facing the Environment Agency when implementing the WFD in the region.

\subsection{The WaterProof Northwest scenarios: method and output}

Scenario development was guided by a core project team involving staff from the University of Manchester, the Mersey Basin Campaign (a partnership organisation with a remit to improve the water environment of the river Mersey), the Environment Agency and United Utilities (a private sector water company responsible for water supply and waste water treatment in Northwest England). The research methodology included 15 semi-structured interviews involving individuals from the water sector, local government, major developers, environmental organisations and regional bodies. Six workshops involving 26 key regional stakeholders helped identify and refine the list of drivers, aided the construction of the scenarios and then collaboratively discussed their implications. Fig. 1 summarises the scenario development method.

The first stage of WaterProof Northwest was to explore drivers of change with the potential to affect the future growth and development of the region, many of which will also directly and indirectly influence the processes of developing and implementing responses to manage the water environment. A challenging aspect of horizon scanning projects such as WaterProof Northwest is not to simply recognise the diverse and wide ranging factors that drive change, but rather in selecting and focussing in on the few factors that are most relevant to the issue being investigated. A participatory method involving a review of relevant literature, workshops and interviews involving a range of stakeholders identified 51 potential drivers with the potential to influence Northwest England through to 2030. Through a series of stakeholder workshops where the merits and impact of each driver were discussed in groups, this 'long list' was revised down to 10 key drivers of change perceived to have the potential to impact most significantly on water in the region. This final grouping of drivers also reassembled aspects that were closely related together within one key heading in order to integrate previously fragmented issues, such as climate change, social conscience and behaviour, and regulation and legislation. The 'short list' is detailed in Table 1.

With the key drivers of change identified, the next stage of the process was to begin to develop the scenarios themselves. The WaterProof Northwest scenarios are based around the classic

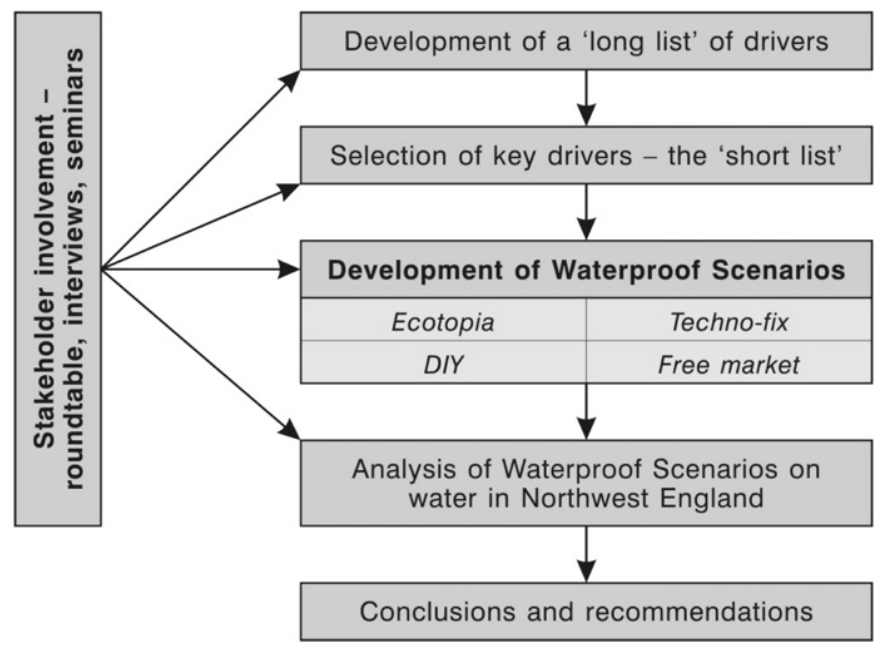

Fig. 1. The WaterProof Northwest scenario development methodology. 
Table 1

WaterProof Northwest drivers of change - the short list.

\begin{tabular}{ll}
\hline - Social conscience and behaviour & - Devolution of decision making \\
- Leadership & - Investment \\
- Climate change & - Population and demography \\
- Appliance of science & - Institutional and economic structures \\
- Land use change and management & - Regulation and legislation
\end{tabular}

'quadrant' approach used to organise recognised scenario sets such as those developed by the IPCC (IPCC, 2000), the Environment Agency (2006) and the UK government's Foresight programme (Evans et al., 2004). Four contrasting scenarios, Ecotopia, Technofix, DIY and Free Market, were created by combining two axes representing drivers regarded by the project's stakeholder group as most fundamental to the future of the region and its water environment (Fig. 2). The two axes selected, governance systems and societal values, collectively encompass issues relevant to all of the 10 key drivers of change. In the context of this project, governance relates to the exercise of power and influence through government policy and decision making. The focus is on actions and decisions within the public sector (at national, regional and local scales), that influence the private sector and civil society. Two broad governance approaches were conceived; proactive and laissez faire. Proactive governance systems imply an engaged state sector working to actively respond to emerging issues through legislation and regulation, whereas laissez faire governance approaches encapsulate a smaller state sector and a leading role for the private sector. In terms of the second axis, the values held by any society are a defining factor in the success or failure of a wide range of initiatives from education to environmental management. Community and consumerism were identified as two opposing approaches to characterising societal values, with the former encapsulating more localised and low-impact lifestyles and the latter a high consumption and free-market growth outlook.

With the key drivers of change and the quadrants identified, the process then turned to developing the scenarios themselves. Participatory workshops and interviews provided information and insights to enrich the scenarios and the storylines that sit within them. Fig. 3 provides a summary of the key features of each of the four scenarios, which were named Ecotopia, Techno-fix, DIY and Free market. The drivers remain the same for each scenario. However, their interpretation differs, thereby portraying contrasting possible futures for the Northwest region and its water environment through to 2030 .

\subsection{Using the WaterProof Northwest scenarios}

The WaterProof scenarios are not designed to create an illusion of certainty, but rather to inform strategic decision making and

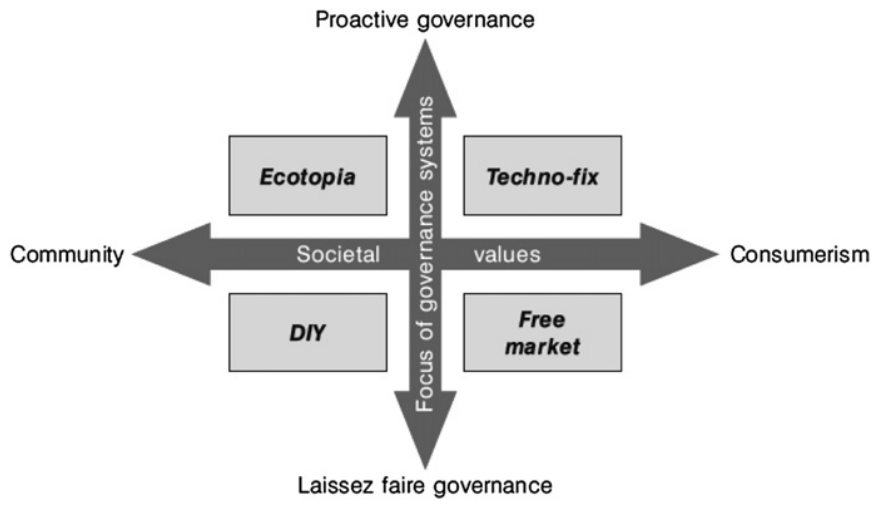

Fig. 2. Structure of the WaterProof Northwest scenarios. raise awareness of future challenges and opportunities in the context of the water environment and the implementation of the WFD. Indeed, the scenarios demonstrate that the array of issues impacting on water management is potentially huge, and in many cases these are unquantifiable as they relate to societal and political change. Analysis of the scenarios within the project highlighted four overarching and cross-cutting themes with significant potential to influence the future of water and the WFD in Northwest England. These relate to the state of the economy, climate change, governance and regulation, and social issues. Although these themes emerged from an analysis of one particular region, the issues raised are largely generic and therefore transferable to other areas of the UK, and to other developed nations experiencing the impact of uncertain drivers of change on the water environment and water resource management. Indeed, the scenarios themselves are of potential use to organisations concerned with managing the water environment both within the UK and beyond.

1. The state of the economy: The type and direction of economic growth and development and related policy will play a central role in the effectiveness of responses to implement the WFD, and in terms of the quality of the water environment more generally. However, the current era of economic instability demonstrates that it is simplistic to assume that pressures linked to economic growth, for example housing development and greater energy use, are the key threats to the water environment. A lack of public and private capital can also endanger water and water resource management, as can a related erosion of environmental legislation where perceived as a barrier to generating growth. Closely linked to economic growth and stability is the issue of investment in water-related infrastructure. At present, in England and Wales the delivery of the WFD is influenced to a large extent by the capital investment programmes of the utilities companies responsible for supplying and treating water. The long-term viability of this model cannot be assured in an era of austerity and volatility in capital markets. Levels of economic prosperity will continue to exert a strong influence on the quality and management of water in the Northwest region and beyond.

2. Climate change: Climate change has a clear role to play across all of the WaterProof Northwest scenarios, and will influence water in numerous ways. There is uncertainty over the severity of future climate change, although recent research suggests that the higher end of the projections is looking increasingly likely (Betts et al., 2011). This uncertainty is recognised by the European Commission (European Communities, 2009), who note that a range of climate change scenario projections should be considered as part of implementing the WFD. Although the direct impacts of climate change on variables including temperature and precipitation are important for the water environment and water use, these could potentially be less significant in the Northwest, over the medium term at least, than the indirect impacts related to a changing climate on a global scale. Indeed, under certain scenarios, a concerted response to climate change through actions to mitigate greenhouse gas emissions will begin well before the direct impacts take full effect. For example, issues such as the move to a low carbon economy, and potentially carbon pricing, would dramatically affect how water is treated and consumed. Further, climate change induced migration and food security issues are particularly relevant to future levels of water consumption, and could place additional pressures on water supplies in regions such as Northwest England. The nature of the direct and indirect impacts of climate change will depend in turn on the direction of other drivers, including public 


\begin{tabular}{|c|c|}
\hline $\begin{array}{c}\text { Ecotopia } \\
\text { Proactive governance, community values }\end{array}$ & $\begin{array}{c}\text { Techno-fix } \\
\text { Proactive governance, consumerist values }\end{array}$ \\
\hline $\begin{array}{l}\text { Key features } \\
\text { - Society values the natural environment highly } \\
\text { - Low carbon economy, EU carbon directive } \\
\text { - Blue energy revolution for the region } \\
\text { Water environment implications } \\
\text { - Climate change adaptation - flooding, water supply } \\
\text { - Water bills rise, lower per-capita water use } \\
\text { - Significant investment in water utilities } \\
\text { - Ecosystem focused water management approach }\end{array}$ & $\begin{array}{l}\text { Key features } \\
\text { - High consumption, intensification of related trends } \\
\text { - Limited societal environmental awareness } \\
\text { - Golitical/private sector push for sustainable growth } \\
\text { Water envir honment implications } \\
\text { - Climate adaptation imperative accepted } \\
\text { - Reluctance to manage consumer water demand } \\
\text { - Regulation/legislation targeted at private sector }\end{array}$ \\
\hline $\begin{array}{c}\text { DIY } \\
\text { Laissez faire governance, community values }\end{array}$ & $\begin{array}{c}\text { Free market } \\
\text { Laissez faire governance, consumerist values }\end{array}$ \\
\hline $\begin{array}{l}\text { Key features } \\
\text { - The recession leads into a protracted depression } \\
\text { - Spending cutbacks in the public and private sector } \\
\text { - Environmental and social problems intensify } \\
\text { - Patchy and piecemeal community responses } \\
\text { Water environment implications } \\
\text { - Limited legislation, regulation or investment } \\
\text { - Devolved responsibility - communities/private sector } \\
\text { - Water is valued more highly by the public }\end{array}$ & $\begin{array}{l}\text { Key features } \\
\text { - Economic growth 'at all costs' } \\
\text { - Scaling back of state, business focused policy } \\
\text { Benefits to some and costs to many - inequality } \\
\text { Water environment implications } \\
\text { - Falling investment levels in water infrastructure } \\
\text { - Lower environmental targets and less regulation } \\
\text { - Climate change and immigration pressure services } \\
\text { - Inequitable climate adaptation, personal resilience }\end{array}$ \\
\hline
\end{tabular}

Fig. 3. Summary of the WaterProof Northwest scenarios.

environmental attitudes, legislation and technology, which may either exacerbate or help to contain the impacts of climate change related effects on water.

3. Governance and regulation: The WFD is essentially a planning framework developed to manage the water environment over the long-term. Its effectiveness will be influenced by the nature of governance approaches supporting the Directive (and environmental management more broadly) within the European member states responsible for WFD delivery. The scenarios suggest that governance, and associated issues such as political leadership, the balance between central government control and local autonomy, and the extent to which environmental legislation and regulation is enforced, will have significant implications for the implementation of the WFD. The future viability of the Directive itself may even be affected by the stability of governance arrangements at the EU level. Governance frameworks have the potential to change significantly and rapidly over the coming decades, particularly where regulation is seen to affect economic growth. The key concern remains that without a supportive framework of legislation and regulation underpinning environmental planning and management, the Directive has limited potential to be effective.

4. Social issues: The attitude of society to the natural environment plays an important role in each of the WaterProof Northwest scenarios. This is due to the impact that people's behaviour and actions have across a number of the key drivers of change connected to water. For example, political leadership and related systems of legislation and regulation are underpinned, or in some cases undermined, by the degree of public support for environmental policies. The value that society attaches to water will also have a direct effect on water quality and usage. There are also potential social impacts associated with meeting the goals of the WFD which should be recognised. A legislated approach to improving the water environment implies that resources are prioritised that may have otherwise been used for different purposes or social goals. Moreover, whilst higher consumer bills would enable increased investment in water supply and waste water treatment infrastructure, this strategy may disproportionately hit poorer sections of society if water bills rise as a result. Societal values and social concerns can shift as a result of, for example, the influence of fashions and trends, the media and major events such as floods or droughts.

The application and analysis of the WaterProof Northwest scenarios offer lessons for the specific issue of delivering the WFD in Northwest England (and other parts of Europe). The scenarios also emphasise the diverse challenges facing organisations responsible for developing and implementing long-term environmental plans and strategies. WaterProof Northwest demonstrates that the effectiveness of actions to implement strategic responses in the water sector will be influenced by a multitude of social, environmental and economic factors. In the case of the WFD, although the Environment Agency is charged with delivering the Directive in England and Wales, a critical finding of the scenarios exercise was that their success in meeting goals related to the Directive will be influenced by wider external forces that lie beyond the control of the Agency. For example, prevailing political attitudes, economic growth rates and the availability of capital, levels of public environmental awareness and the pace of technological change will all be central to the future of the water environment. Whilst the Agency is well placed to manage the WFD from an administrative and procedural standpoint, through the development of RBMPs and the regulation of sectors influencing water quality and quantity, it is a passive recipient of many of the broader drivers that affect water, highlighting the need for synergies in knowledge generation and partnership working, which the process of scenario development can support.

The WaterProof Northwest scenarios offer a perspective of an EU Directive whose long-term success rests to a certain degree outside the scope of competent authorities charged with its delivery. In effect, far from reducing uncertainty, the development and analysis of the WaterProof Northwest scenarios have provided a more ambiguous, yet realistic, view of a complex piece of legislation subject to strong external forces. It is likely that environmental policy initiatives across a range of themes and sectors will be beset by the same fundamental challenge. Perhaps in view of uncertain 
situations such this, recent response approaches include the move towards more evidence-based methodologies within environmental planning. The development of associated indicators and targets is a good example, such as the 68 indicators used to monitor UK progress towards sustainable development (Defra, 2010). Another common response to uncertainty and complexity is to gather more data in an attempt to reduce these effects. For example, city planners may look to gather information on demographic projections when developing planning policies around housing growth in their locality. Perhaps incongruously, however, increasing information gathering and analysis may not actually reduce uncertainty; it may rather highlight, in the same way as the WaterProof Northwest scenarios have done in the case of water and the WFD, such a daunting degree of complexity that traditional mono-disciplinary and short term governance approaches and policies are revealed to be largely ineffective or inadequate. In reality therefore, and possibly counter intuitively, more information may actually heighten feelings of uncertainty.

And here is the conundrum. The complexity, connectivity and scale of systems with the ability to influence the environment makes the need for future-oriented planning more critical, whilst at the same time challenging the silo based and quantitative methods and governance structures currently utilised within planning and strategy making. Forces beyond the perception, scope and control of individual institutions can clearly affect the success of plans and policies that they develop, and scenario construction offers an insight into how these wider influences can be constructively incorporated into existing processes.

It is crucial that organisations responsible for the management of environmental resources have the opportunity to acknowledge and reflect on key drivers of change with relevant stakeholders. The process of developing scenarios, which often brings together a range of agencies to engage in strategic thinking, is valuable in building these relationships. Partnership working is an appropriate response to working with uncertainty, with connections important both vertically across spatial boundaries and horizontally between sectors. Sharing intelligence and insights can help to generate consensus on significant issues and enhance capacity to respond to the circumstances that they create. In this way, the plans of one agency may support, rather than undermine, the objectives of another. Further, maintaining sufficient organisational flexibility is also crucial within sectors impacted on by a range of multifaceted drivers of change. Overly rigid structures run counter to the nature of the environmental issues that key organisations are tasked with addressing. These bodies should ideally incorporate a similar degree of dynamism within their structures and processes as that which characterise the processes influencing the quality and use of environmental resources.

\section{Reflections on the use of scenarios in environmental planning}

Environmental planning and management in the 21st Century will be faced by a range of shocks and 'wild cards' that will affect, amongst other things, the quality and use of natural resources and the structure of organisations and legislative frameworks in place to govern them. The ongoing and evolving financial crisis is perhaps the most visible recent case of an event that was not widely anticipated, yet is set to have massive repercussions for environmental agendas. For example, associated public sector spending cuts in countries such as England and Wales have led to budget constraints and staff losses within both national level environmental agencies and the environment departments of local municipal authorities. Furthermore, the UK government has placed all of Britain's 278 environment laws under review with a view to considering their potential impact on growth (Stratton, 2011). The capacity to mount both strategic and local responses to environmental challenges may be weakened as a result. A recent UK study looking at climate change activity in local authorities (municipalities) (Green Alliance, 2011) found that in response to the changing legislative context in this area, $37 \%$ will be de-prioritising climate change with a further $28 \%$ narrowing their ambitions in this field. Although $35 \%$ of authorities remain committed to mitigating and adapting to climate change, this example highlight the implications of recent shifts in governance approaches for environmental planning and management.

Although there may be weak signals that indicate the impending possibility of seismic shifts such as these, it is difficult for decision makers to recognise and act on many of the key forces shaping the future. This is due in part to the lack of awareness and application of methods and techniques that can help build a level of strategic insight around current and potential future drivers of change. Greater attention could usefully be paid to these approaches, including scenario development, which can support futures oriented approaches to planning and decision making. Used effectively, scenarios have the potential, amongst other benefits such as raising awareness of possible drivers of change, to actively stimulate the development of more robust future oriented decisions and actions. Despite the potential value of scenarios, and the fact that they have several decades of history of use in practice, they still remain on the sidelines of mainstream planning and policy making both in the public and private sectors.

Although planning and decision making approaches may ideally need to be designed in a way that can more effectively tolerate uncertainty and embrace complexity, this runs counter to the norms of evidence-based decision making which demands certainty to act. Methodological guidance is needed in order to focus scenario development more squarely on the requirements of planners and decision makers. The IPCC has recently encouraged researchers to progress the next generation of global climate change scenarios using a parallel rather than sequential methodology, twinning scenario development with climate modelling within an integrated and reflexive process. This change in approach is proposed in order to increase the utility of scenario outputs for decision makers engaging in climate change agendas (Moss et al., 2010). Further, the European Environment Agency (EEA, 2009) suggests that inductive rather than deductive scenario approaches are required to improve their ability to assist organisations in responding to the shocks and challenges that increasingly characterise the modern world. This suggests that new theoretical underpinnings of scenario and horizon scanning approaches are needed, potentially stemming from observations of application of these techniques in practice.

The potential effectiveness of scenario exercises in practice is influenced by organisational structures and norms of behaviour. As noted by the European Environment Agency (2009: 11), "Longterm thinking cannot provide a technical 'fix' for a context that is driven by short term concerns". Indeed, incremental and rational planning processes are mostly designed to deliver short term and simply defined goals, and often cannot adequately appreciate and respond to the high levels of complexity inherent in many organisations and systems. They may therefore struggle to deliver desirable holistic futures in the face of complexity and uncertainty (Ball, 2001). Ball (2001) further states that environmental problems are often too complex and too dependent on stakeholder participation for top-down fragmented approaches to be an effective model for environmental planning and management.

Without an organisational culture that is responsive to change, the effectiveness of scenarios in practice may be limited. Scenarios expose the governance challenges associated with absorbing the 
outcomes of futures exercises into planning and decision making, with issues associated with long-term planning of the water environment under the WFD being a good case in point. The outputs of scenario exercises reflect back on, and often lay bare, rigid and siloed approaches that characterise many decisions linked to environmental planning and management, which jeopardises the creation of effective responses to these agendas. Ultimately, organisational cultures and management structures need to be flexible enough to take on board the findings of scenario studies.

The WaterProof Northwest case study demonstrates that competent authorities may be held responsible for a failure to hit targets, in this case those prescribed by the WFD, even though the factors underlying this failure may be out of their control. Whilst this may initially seem unjust, it is entirely in the power of organisations to evolve away from rigid approaches to long-term planning and decision making. Instituting collaborative processes would also help to extend the influence of competent authorities beyond existing governance structures, with embedded learning raising the possibility of shared, reinforcing goals. However, it is recognised that this is not currently standard practice, and that targeted guidance and support will be needed to support a change in approach of this nature. Indeed, it is recognised that there is a lack of frameworks supporting 'visioning' exercises in planning (Shipley, 2002).

An alternative to encouraging organisational structures to evolve towards more holistic and collaborative decision making approaches, that are better suited to responding to complex environmental problems such as those linked to water, would be to amend the legislation prescribing action in these fields. However, is it viable or even appropriate for legislation such as the WFD to be reconceived in recognition of the influence of unpredictable chains of cause and effect on related decisions and actions? Ultimately it may be unproductive to single out pieces of legislation in this way. In this case, it may be more valuable for additional guidance to be produced outlining the scope of drivers of change influencing the achievement of the WFD's goals, and highlighting the utility of exercises such as scenario planning as a potential response.

Notwithstanding the changing nature, scale and scope of many environmental problems, uncertainty and complexity have always been attached to decisions and actions. There is, however, an increasing awareness of the existence and effect of these issues (Renn, 2008; Smil, 2008). This awareness has the potential to act as a parallel force - one which could galvanize or stifle decision making. Indeed, in some fields the pervasiveness of these factors is such that one might be forgiven for questioning the value of forward planning. Can we effectively conduct a future-orientated activity such as planning for long-term water management, for example, when the drivers of change influencing the issue operate across multiple and interconnecting scales and sectors, many of which the appointed decision making body holds no influence over? It is significant to reflect here that Hodgkinson and Wright (2002) found that scenarios can be less effective in motivating beneficial change in planning and decision making where a threat is identified for which an organisation has no viable response. It is not that organisations do not recognise such issues, it is just that, in the case of planning for climate change for example, the nature of necessary responses may sometimes overwhelm them (Campbell, 2006).

This article has drawn on a case study of the implementation of the WFD to demonstrate that this doesn't have to be the case. Quantitative and silo-based decision making norms can lead to institutional paralysis and an inability to break out of cyclical reactive responses to shocks. However, the dualistic benefits offered by scenarios - linked to their process and output - presents a mechanism to both recognise and engage with external forces that can threaten the achievement of internal goals. In this sense, scenarios can be viewed as a complementary decision making methodology to help build more collaborative and resilient future outcomes.

\section{Acknowledgements}

The authors wish to thank the Environment Agency for England and Wales who funded the WaterProof Northwest project, and the variety of stakeholders who helped with the data collection, without either of which this article would not have emerged. The valuable input provided by Professor Graham Haughton on earlier drafts of this article were also greatly appreciated, as were the constructive suggestions of the referees who commented. The WaterProof Northwest scenarios can be viewed at: http://www.sed. manchester.ac.uk/research/cure/research/\#WaterProof.

\section{References}

Ball, J., 2001. Environmental future state visioning: towards a visual and integrative approach to information management for environmental planning. Local Environment 6 (3), 351-366.

Betts, R., Collins, M., Hemming, D., Jones, C., Lowe, J., Sanderson, M., 2011. When could global warming reach $4{ }^{\circ} \mathrm{C}$. Philosophical Transactions of the Royal Society $369,67-84$.

Bezold, C., 2010. Lessons from using scenarios for strategic foresight. Technological Forecasting and Social Change 77 (9), 1513-1518.

Bishop, P., Hines, A., Collins, T., 2007. The current state of scenario development: an overview of techniques. Foresight $9(1), 5-25$.

Brown, V.A., Harris, J.A., Russell, J.Y., 2010. Tackling Wicked Problems - through the Transdisciplinary Imagination. Earthscan, London.

Cabinet Office, 2001. A Futurist's Toolbox: Methodologies in Futures Work. Cabinet Office Performance and Innovation Unit, Cabinet Office, London.

Campbell, H., 2006. Is the issue of climate change too big for spatial planning? Planning Theory and Practice 7 (2), 201-230.

Carter, J., White, I., 2010. WaterProof Northwest Final Report. Available at: http:// www.sed.manchester.ac.uk/research/cure/research/\#WaterProof.

Chave, P., 2001. The EU Water Framework Directive: an Introduction. IWA Publishing, London

Clark, W.C., Mitchell, R.B., Cash, D.W., 2006. Evaluating the influence of global environmental assessments. In: Mitchell, R.B., Clark, W.C., Cash, D.W., Dickson, N.M. (Eds.), Global Environmental Assessments: Information and Influence. MIT Press, Cambridge.

Defra, 2010. Measuring Progress: Sustainable Development Indicators 2010. Defra, London.

Environment Agency, 2006. Environment Agency Scenarios 2030. Environment Agency, Bristol.

Environment Agency, 2009. River Basin Management Plan: Northwest River Basin District. Environment Agency, Bristol.

European Communities, 2009. Common Implementation Strategy for the Water Framework Directive (2000/60/EC): Guidance Document No. 24 - River Basin Management in a Changing Climate. European Commission, Brussels.

European Environment Agency (EEA), 2000. Cloudy Crystal Balls: an Assessment of Recent European and Global Scenario Studies and Models. European Environment Agency, Copenhagen.

European Environment Agency (EEA), 2001. Scenarios as Tools for International Environmental Assessments. European Environment Agency, Copenhagen.

European Environment Agency, 2009. Looking Back on Looking Forward: a Review of Evaluative Scenario Literature. European Environment Agency, Copenhagen.

European Union, 2000. Directive 2000/60/EC of the European Parliament and of the Council Establishing a Framework for Community Action in the Field of Water Policy [the Water Framework Directive]. Official Journal of the European Communities L327, Brussels.

European Union, 2007. Directive 2007/60/EC: on the Assessment and Management of Flood Risks. Official Journal of the European Communities L288, Brussels.

Evans, E., Ashley, R., Hall, J., Penning-Rowsell, E., Saul, A., Sayers, P., Thorne, C., Watkinson, A., 2004. Foresight Flood and Coastal Defence: Phase 1 Technical Report Drivers, Scenarios and Work Plans. Office of Science and Technology, London.

Funtowicz, S.O., Ravetz, J.R., 1991. A new scientific methodology for global environmental issues. In: Costanza, R. (Ed.), Ecological Economics: the Science and Management of Sustainability. Columbia University Press, New York, pp. 137-152.

Garb, Y., Pulver, S., VanDeveer, S., 2008. Scenarios in society, society in scenarios: toward a social scientific analysis of storyline-driven environmental modelling. Environmental Research Letters 3 (4), 1-8. 
Green Alliance, 2011. Is Localism Delivering for Climate Change? Emerging Responses from Local Authorities, Local Enterprise Partnerships and Neighbourhood Plans. Green Alliance, London.

Hodgkinson, G., Wright, G., 2002. Confronting strategic inertia in a top management team: learning from failure. Organisation Studies 23, 949-977.

Hsu, C., Sandford, B., 2007. The Delphi technique: making sense of consensus, practical assessment. Research and Evaluation 12 (10), 1-8.

Hulme, M., Dessai, S., 2008. Negotiating future climates for public policy: a critical assessment of the development of climate scenarios for the UK. Environmental Science and Policy II, 54-70.

Intergovernmental Panel on Climate Change (IPCC), 2000. IPCC Special Report Emissions Scenarios Summary for Policy Makers. IPCC, New York.

Johnson, C.L., Tunstall, S.M., Penning-Rowsell, E.C., 2005. Floods as catalysts for policy change: historical lessons from England and Wales. International Journal of Water Resources Development 21 (4), 561-575.

Kingdon, J., 1984. Agendas, Alternatives and Public Policies. Harper Collins, New York. Linstone, H., Turoff, M., 1975. In: The Delphi Method: Techniques and Applications. Addison Wesley.

Meadows, D., Meadows, D.L., Randers, J., Behrens, W., 1972. The Limits to Growth. Universe Books, New York.

Moss, R., Edmonds, J., Hibbard, K., Manning, M., Rose, S., van Vuuren, D., Carter, T., Emori, S., Kainuma, M. Kram, M., Meehl, G, Mitchell, J, Nakicenovic, N. Riahi, K., Smith, S., Stouffer, R., Thomson, A., Weyant, J., Wilbanks, T., 2010. The next generations of scenarios for climate change research and assessment. Nature 463, 747-756.

Owens, P., Owens, S., 1991. The Environment, Resources and Conservation. Cambridge University Press, Cambridge.
Rankin, P., 2005. Global scenarios: background review for the millennium ecosystem assessment. Ecosystems 8, 133-142.

Renn, O., 2008. Risk Governance: Coping with Uncertainty in a Complex World Earthscan, London.

Rittel, H., Webber, M., 1973. Dilemmas in a general theory of planning. Policy Sciences 4, 155-169.

Sadar, Z., 1999. Rescuing All Our Futures: the Future of Future Studies. Praeger Paperback, Santa Barbara.

Shipley, R., 2002. Visioning in planning: is the practice based on sound theory? Environment and Planning A 34, 7-22.

Skaburskis, A., Teitz, M., 2003. Forecasts and outcomes. Planning Theory and Practice 4, 429-442.

Smil, V., 2008. Global Catastrophes and Trends: the Next 50 Years. MIT Press, London. Stratton, A., 2011. Environmental Campaigners Angry as Green Laws Labelled as Red Tape, The Guardian, 17 April. Available at: http://www.guardian.co.uk/politics/2011/ apr/17/environment-green-laws-red-tape?CMP=twt_gu (accessed 20.04.11.).

The Henley Centre, 2001. Best Practice for Strategic Futures Work. The Henley Centre, London.

Van Notten, P.W.F., Rotmans, J., Marjolein, B.A., van Asselt, D., Rothman, S., 2003. An updated scenario typology. Futures 35, 423-443.

Voros, J., 2006. A classification framework for prospective methods. Foresight 8, 43-56.

Wack, P., 1985. Scenarios: uncharted waters ahead. Harvard Business Review 63 (5), 72-89.

White, I., 2010. Water and the City: Risk, Resilience and Planning for a Sustainable Future. Routledge, London.

Wisner, B., Blaikie, P., Cannon, T., Davis, I., 2004. At Risk: Natural Hazards, People's Vulnerability and Disasters. Routledge, London. 